\title{
Pathogenesis, presentation and classification of late autoinflation of the breasts: case report and literature search
}

\author{
Umar Daraz Khan \\ Aesthetic Plastic Surgeon, Reshape House, West Malling, Kent ME19 6QR, UK. \\ Address for correspondence: Mr. Umar Daraz Khan, Aesthetic Plastic Surgeon, Reshape House, 2-4 High Street, West Malling, Kent ME19 \\ 6QR, UK. E-mail: Mrumarkhan@aol.com
}

\begin{abstract}
Aim: Autoinflation of the breast following mammoplasty using breast implants can be divided into early and late. Early autoinflation of the breast is commonly due to haematoma. Late autoinflation of the breast is an uncommon complication and its true incidence is not known due to the paucity of its reporting. Methods: A retrospective review was performed of the available charts for 2,772 consecutive bilateral primary, secondary augmentation mammoplasties and mastopexy with augmentation mammoplasties by the author between April 1999 and February 2015. Each breast was taken as a single unit for a total of 5,544 breasts. Results: There were 2,334 patients in primary augmentation mammoplasty, 258 in secondary augmentation mammoplasty and 180 in simultaneous mastopexy with augmentation mammoplasty. There were three autoinflation of breasts due to late seromas identified in the series. All patients presented at least six months following augmentation mammoplasty and all had textured implants place in muscle splitting submuscular pocket. There was no late seroma noted in secondary augmentation mammoplasty or simultaneous mastopexy with augmentation mammoplasty. All patients were treated conservatively without a recurrence. Conclusion: Late autoinflation of the breast due to seroma is an uncommon clinical complication and can be treated conservatively in the first instance.
\end{abstract}

Key words:

Anaplastic large cell lymphoma; autoinflation of the breast; haematoma; seroma of breast; anaplastic large cell lymphoma

\section{INTRODUCTION}

Since the introduction of implants in 1962, augmentation mammoplasty has become a widely accepted procedure for aesthetic and reconstructive reasons. ${ }^{[1]}$ An estimated five to 10 million women have breast implants worldwide. ${ }^{[2]}$ Early and late complications following mammoplasty are many. It is beyond the scope of this article to address all the arising complications. Intracapsular fluid is a common finding and has been reported with an incidence of $15 \%$.

\begin{tabular}{|l|l|}
\hline \multicolumn{2}{|c|}{ Access this article online } \\
\hline Quick Response Code: & Website: \\
& http://par.oaepublish.com/ \\
& \\
& \\
\hline
\end{tabular}

The accumulation of fluid was minimal and did not lead to swelling of the breast nor was it the reason for revision surgery. ${ }^{[3,4]}$

Autoinflation of the breast is a clinical condition that can be defined as a sudden or spontaneous swelling of the breast following augmentation mammoplasty due to collection

This is an open access article distributed under the terms of the Creative Commons Attribution-NonCommercial-ShareAlike 3.0 License, which allows others to remix, tweak and build upon the work non-commercially, as long as the author is credited and the new creations are licensed under the identical terms.

For reprints contact: service@oaepublish.com

How to cite this article: Khan UD. Pathogenesis, presentation and classification of late autoinflation of the breasts: case report and literature search. Plast Aesthet Res 2016;3:31-5.

Received: 23-08-2015; Accepted: 04-12-2015 
of fluid rather than the implant filler. The process may or may not proceed or follow with an incidence of trauma or injury. Early known causes of autoinflation of breast are infection, haematoma or seroma with a reported incidence of $0.5 \%$ and $0.7 \%$ respectively. ${ }^{[5,6]}$ Causes of late onset of autoinflation of breasts are many but these are not clearly defined on the basis of its aetiology, type of implants or site of accumulation of the fluid. Autoinflation of breasts may or may not be associated with implant rupture. Rupture of silicone implants is normally silent and rarely leads to loss or increase in volume. ${ }^{|7|}$ Ruptures may also present with loss of shape or consistency ${ }^{[8]}$ or axillary lymphadenopathy. ${ }^{[9,10]}$ Implant rupture may occasionally present as spontaneous autoinflation of the breast. ${ }^{[1-13]}$ In contrast saline implant can deflate following its rupture. Rarely a saline implant can present with autoinflation of the breast without a rupture or breach in the shell of the implant..$^{[14]}$

The presentation of anaplastic large cell lymphoma (ALCL) following augmentation mammoplasty also presents as an autoinflation of the breast. There is increasing awareness of ALCL which merits special attention.

The current article looks at the management and presentation of three patients. These patients presented with spontaneous autoinflation of the breasts due to late seroma. Also included is literature search to discuss various causes, locations and type of the texturing of the devices for the development of autoinflation of breast.

\section{METHODS}

A retrospective review was performed of the available charts for 2,772 consecutive bilateral primary, secondary augmentation mammoplasties and mastopexy with augmentation mammoplasties performed by the author between April 1999 and February 2015. Each breast was taken as a single unit for a total of 5,544 breasts.

\section{RESULTS}

There were 2,334 patients in primary augmentation mammoplasty, 258 in secondary augmentation mammoplasty and 180 in simultaneous mastopexy with augmentation mammoplasty groups. A total of 3 autoinflation of breasts due late seroma were identified in the series [Table 1]. All patients presented at least 6 months following augmentation mammoplasty and all had textured implants place in muscle splitting submuscular pocket. There was no autoinflation due to late seroma noted in secondary augmentation mammoplasty or simultaneous mastopexy with augmentation mammoplasty. All patients were treated conservatively without a recurrence.

\section{Case I}

A 34-year-old mother of 2 children was interested in breast augmentation procedure. The augmentation mammoplasty was performed using $605 \mathrm{~mL}$ TRF Allergan Natrelle INSPIRA cohesive gel silicone textured round implants in muscle splitting pocket. She had an uneventful recovery.
Eight months following augmentation mammoplasty, she presented with spontaneous autoinflation of her right side. There was no recollectable history of trauma or injury. She was treated with antibiotics, cold compress, support garments and was followed up with regular intervals. The swelling gradually subsided within 2 months without surgical intervention and there was no recurrence for 8 years [Figure 1].

\section{Case 2}

A 25-year-old mother of 1 child showed interest in augmentation mammoplasty following the loss of volume of her breasts. Augmentation mammoplasty was carried out using 310 TRM Allergan Natrelle INSPIRA cohesive gel silicone textured round implants in muscle splitting pocket. She had an uneventful recovery and all settled well. Eight months following her surgery, she presented with quick onset autoinflation of her right breast. She was treated conservatively with antibiotics, cold compress and support garment. The swelling subsided in 8 weeks without surgical intervention and without recurrence for 6 years [Figure 2].

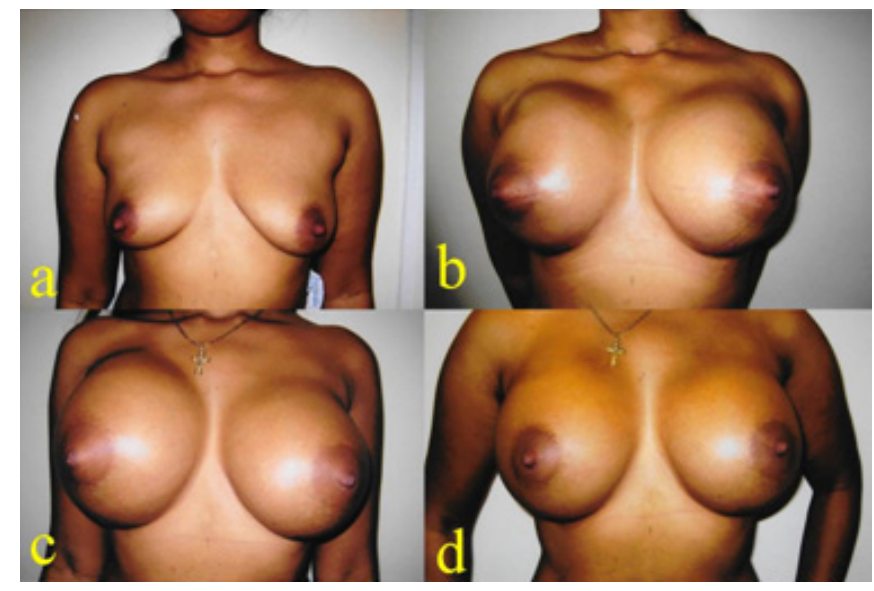

Figure 1: (a) Preoperative picture of a 34-year-old patient; (b) six weeks following augmentation mammoplasty with 605 TRF Allergan Natrelle textured implants; (c) the patient presented with massive right-sided swelling 8 months following mammoplasty; (d) two months following presentation with autoinflation due late seroma. The patient was treated conservatively

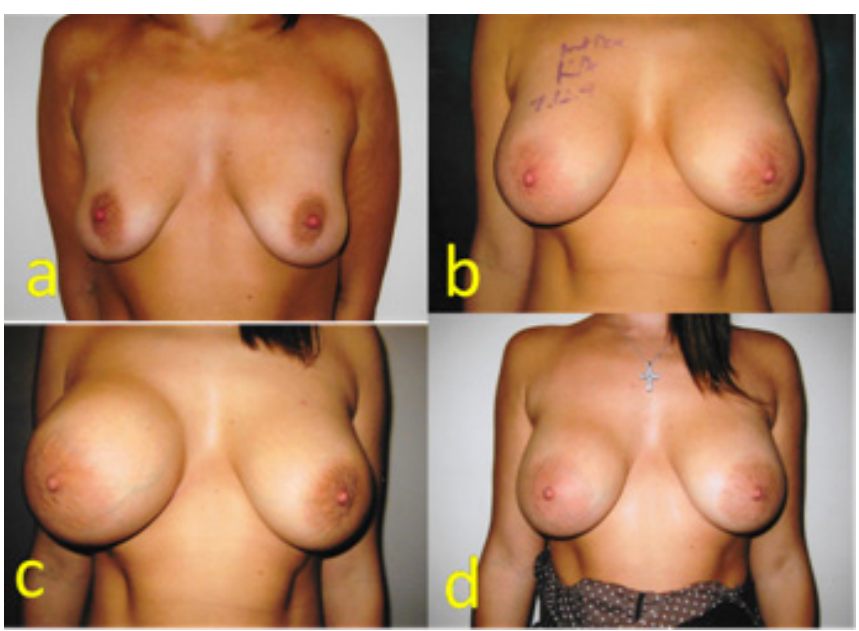

Figure 2: (a) Preoperative picture of a 25-year-old patient; (b) six weeks following augmentation mammoplasty with 310 TRM Allergan Natrelle textured implants; (c) the patient presented with right-sided spontaneous swelling 8 months following mammoplasty; (d) three months following presentation with autoinflation due to late seroma. The patient was treated conservatively 


\section{Case 3}

A 19-year-old young female presented with asymmetrical breast along with right breast ptosis. She had her augmentation mammoplasty procedure using $275 \mathrm{~mL}$ on her right and $345 \mathrm{~mL}$ on her left side. Nagor GFX cohesive gel silicone textured implants were placed in muscle splitting pocket a right internal mastopexy was performed at the same time. Eight years later patient presented with an acute onset of right-sided autoinflation of breast. She was reassured and treated conservatively with antibiotics, cold compress and pressure garments successfully without any surgical intervention. Her swelling subsided with in 6 weeks and has been asymptomatic for the last 6 months [Figure 3].

\section{DISCUSSION}

Complications following augmentation mammoplasty though not very common can be early or late. Early complications are infection, haematoma and seroma and may require an urgent surgical intervention. Late complications are infrequent and may include capsular contracture, asymmetry, implant rupture, implant displacement, rippling and synmastia..$^{[5]}$ Revision for these complications can be addressed on the basis of its presentation as an elective procedure. Autoinflation of the breast arising six months or later is an extremely rare presentation. Such autoinflation may have different causes and fluid collection can be intraprosthetic, intracapsular, extracapsular or a combination of the above. The fluid collection is equally seen in implants when silicone,

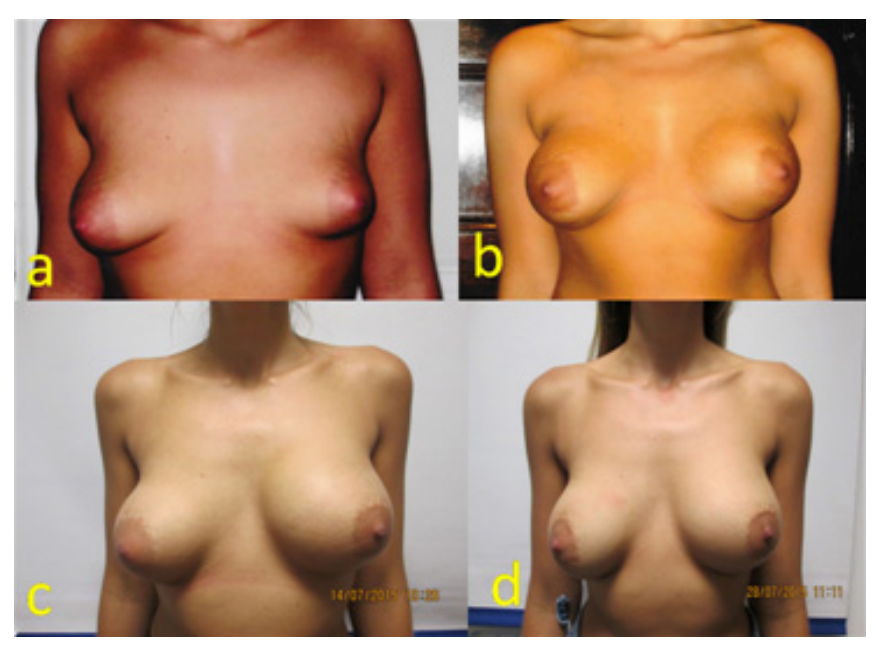

Figure 3: (a) Preoperative picture of a 19-year-old patient presenting with breast asymmetry; (b) eight months following augmentation mammoplasty with right internal mastopexy, patient had $275 \mathrm{~mL}$ GFX Nagor textured implant on her right and $345 \mathrm{~mL}$ GFX Nagor textured implant on her left side; (c) the patient presented with right-sided acute onset swelling 8 years following mammoplasty; (d) three weeks following presentation with autoinflation due to late seroma. The patient was treated conservatively hydrogel or saline is used as filler. The implants can be textured, microtextured, smooth or polyurethane coated. ${ }^{[3,4]}$ However, there is a paucity in literature on the pathogenesis of this condition and is not comprehensively defined on the basis of aetiology, pathogenesis, anatomical location or type of implants.

\section{Intraprosthetic collection of fluid presenting as autoinflation of breast}

Intraprosthetic collection of fluid or sterile pus though not very common has been reported both in saline as well as silicone gel implants. ${ }^{[11-14]}$ However the process differs in the two instances. In saline implants, the shell allows passage of protein macromolecules, predominantly albumin that creates an osmotic gradient across the macroscopically intact silicone shell allowing body fluids to enter the prosthesis. The implants can gain a large volume of fluid and present as autoinflation of the breast. No extracapsular fluid collection has been reported with the process concerning saline implants. ${ }^{[14]}$ On the contrary, intraprosthetic collection of fluid in silicone gel implant is almost always associated with damaged or ruptured shell that may or may not be macroscopically visible and there is almost always intracapsular collection of fluid or sterile pus at the same time..$^{[11-13]}$ The damaged shell allows intracapsular fluid to gain access to the inside of the damaged implant resulting in autoinflation of the breast.

\section{Extracapsular fluid collection presenting as auto inflation of the breast}

Extra capsular collection of fluid following augmentation mammoplasty leading to autoinflation of breast is uncommon. The extracapsular collection of fluid resulting in autoinflation of breast is usually associated with intracapsular collection of fluid. The presentation was noticed following the rupture of poly implant prothese (PIP). The defective silicone escaping into intracapsular and pericapsular spaces starts an inflammatory response that eventually result in large amount of creamy fluid or sterile pus collection leading to autoinflation of breast. The presentation was commonly observed with the rupture of PIP implants..$^{[11,13 \mid}$

\section{Polyacrylamide gel injections}

The similar process of autoinflation of breast is also seen in breast injected with polyacrylamide gel (PAAG). Injection of PAAG does not always produce a distinct layer of capsule. The fluid collection can be in the periphery of the injected material or within injected PAAG. The combination of extra and intra-PAAG collection of fluid may also present as galactocele, seroma or haematoma. ${ }^{\mid 15]}$ In PAAG injection

Table 1: Details of the cases presenting with late seromas in the series

\begin{tabular}{|c|c|c|c|c|c|c|c|}
\hline No. & Age (years) & Implant make & Implant size (mL) & $\begin{array}{l}\text { Implant surface } \\
\text { characteristics }\end{array}$ & $\begin{array}{l}\text { Time since } \\
\text { surgery }\end{array}$ & Pocket of implant & Treatment \\
\hline 1 & 34 & $\begin{array}{l}\text { Allergan } \\
\text { Natralle }\end{array}$ & 605 & Textured & 8 months & $\begin{array}{l}\text { Muscle splitting } \\
\text { submuscular }\end{array}$ & Conservative \\
\hline 2 & 25 & $\begin{array}{l}\text { Allergan } \\
\text { Natralle }\end{array}$ & 310 & Textured & 8 months & $\begin{array}{l}\text { Muscle splitting } \\
\text { submuscular }\end{array}$ & Conservative \\
\hline 3 & 19 & Nagor GFX & 275 & Textured & 8 years & $\begin{array}{l}\text { Muscle splitting } \\
\text { submuscular }\end{array}$ & Conservative \\
\hline
\end{tabular}


the process of autoinflation is multifactorial, it has an inflammatory response resulting in sterile creamy pus like substance collection. Broken down PAAG products creates an osmotic gradient resulting in shift of body fluids into the injected PAAG resulting in autoinflation of the breast. ${ }^{[16]}$

\section{Intracapsular or periprosthetic fluid collection presenting as autoinflation of the breast}

Intracapsular or periprosthetic fluid collection can be seen following augmentation mammoplasty, revision mammoplasty or breast reconstructive surgery using breast implants. The presence of fluid has been reported in $15 \%$ of the revision surgeries and the amount of fluid collected ranged from $0.2 \mathrm{~mL}$ to $20 \mathrm{~mL}$. The fluid can be thick, mucinous, blood stained or serous. ${ }^{[3,4]}$ It is not surprising that collection of fluid in intracapsular space leading to autoinflation of the breast is the most common cause of the late autoinflation. Collection of thick mucinous creamy fluid, resembling like pus but with out positive bacterial culture, is uncommon and is possibly due to a chemical reaction in response to the leaked silicone. ${ }^{[11-13]}$ This type of collection is reported following PIP silicone and hydrogel implant ruptures $^{[11-13]}$ and PAAG injections. ${ }^{[15,16]}$ The cause is the direct contact of the material with the body either through a rupture or following implantation or injection of PAAG.

\section{Autoinflation of breast due to haematoma or blood stained fluid}

This is not the most common form of intracapsular fluid collection presenting as autoinflation of the breast. This type of collection is seen following the separation of the adhered capsule from the textured surface of the implant following a physical force or trauma. These late blood stained fluid or haematomas are especially reported following the use of polyurethane coated implants, where disappearance of polyurethane coating results in inflammation and the implant starts behaving like a textured implant with a highly vascular internal lining of capsule rubbing against the textured surface of the implant. ${ }^{[17]}$

\section{Autoinflation of breast due to late seromas}

The collection of serum in intracapsular space following breast implant surgery is the most common form of autoinflation. The causes can be mechanical, inflammatory, traumatic, hormonal and most importantly malignant (ALCL). Textured implants are more commonly involved and the possible mechanism is the separation of the capsule from the textured surface of the implant. The shearing of the textured surface of the implant on the raw internal vascular surface of the capsular lining starts an inflammatory process resulting in exudation of the fluid that may lead to autoinflation of breast. ${ }^{[17,18]}$

Micro-movements between the micro-textured or smooth implants and capsule can result in synovial metaplasia of the capsular internal lining. The metaplastic lining continuously rubbing against the implant surface can trigger the process. ${ }^{[19,20]}$ Other less well defined possibilities are the presence of subclinical infection, biofilms, any generalised condition leading to low immune response, allergic responses etc. ${ }^{[19]}$ These latter factors need to be investigated further using microbiological assessment of the serum present in the intracapsular fluid along with the chemical analysis of blood and intracapsular fluid samples.

Malignant effusion of the intracapsular space secondary to ALCL is the least common but most alarming cause of autoinflation of the breast. ALCL is a rare type of nonHodgkin lymphoma, which is distinctly different from the primary breast lymphoma of breast. Primary breast lymphomas are overwhelmingly of B-cell as opposed to T-cell phenotype that is associated with breast implants. ${ }^{[21]}$ The incidence of primary breast lymphoma is less than $1 \%$ of all breast neoplasm as compared to an estimated 3 in 100 million women per year of ALCL reported. Implant related ALCL is reported in 34 cases out of estimated 5 to 10 million women with breast implants. ${ }^{[2]}$ These haemopoitic tumours of T-cell origin is extremely rare and the common factor appears to be the texturing of the implants suggesting a site and material specific chronic inflammatory cause. Other possible causes are genetic predisposition and Biofilm organism that may play a contributory role. The condition is not related to the implant fill material. ${ }^{[22]}$ Considering the extreme rarity of ALCL, it is likely that most physicians will never see a single case of ALCL in their career. ${ }^{[2]}$

Following is the recommendations and algorithm as a useful guide to manage late autoinflation of the breast from Bengtson et al. ${ }^{[23]}$ Step 1: conservative treatment. Infection should be ruled out and antibiotics given when in doubt. Aspiration of fluid for culture and cytology when possible; Step 2: imaging ultrasound or magnetic resonance imaging (MRI). Ultrasound may also assist ultrasound-guided aspiration of fluid for culture and cytology; third step: if palpable or MRI evidence of a mass present or in case of refractory or recurrent seroma, surgical exploration is recommended. The procedure includes complete capsulectomy with or without implant replacement.

In the author's practice, the incidence of late seroma was noted in $0.05 \%$ which is much lower when compared to $0.88 \%$ and $1.68 \%$ incidence reported in other series. ${ }^{[17,19]}$ In the current series all three patients who presented with late seromas were treated conservatively using antibiotics and compression bandages. All responded to the treatment and there was no recurrence of autoinflation. One of the patient developed capsular contracture on the side of autoinflation due to late seroma.

In conclusion, implant working group recommendations are available and should be used a guideline for the treatment of late autoinflation of the breast. Late autoinflation of the breast on its own is uncommon and can be treated conservatively in the first instance.

\section{Financial support and sponsorship} Nil.

\section{Conflicts of interest}

There are no conflicts of interest. 


\section{REFERENCES}

I. Cronin TD, Gerow RM. Augmentation mamoplasty: new "natural feel" prosthesis. In:Translational of the third international congress of the plastic surgery. Amsterdam: Excerpta Medica International Congress; 1962. p. 4 I-9.

2. Eaves F 3rd, Nahai F. Anaplastic large cell lymphoma and breast implants: FDA report. Aesth Surg J 201 I;31:467-8.

3. Ann CY, Ko CY, Wager EA, Wong RS, Shah WW. Clinical significance of intracapsular fluid in patients' breast implants. Ann Plast Surg 1995;35:455-7.

4. Ann CY, Ko CY, Wager EA, Wong RS, Shah WW. Micrbial evaluation: 139 implants removed from symptomatic patients. Plast Reconstr Surg 1996;98:1225-9.

5. Khan UD. Breast augmentation, antibiotic prophylaxis and infection: comparative analysis of 1628 primary augmentation mammoplasties to assess the role and efficacy of length of antibiotic prophylaxis. Aesth Plast Surg 2010;34:42-7.

6. Khan UD. Muscle splitting, subglandular and partial submuscular augmentation mammoplasties. A twelve year retrospective analysis of 2026 primary cases. Aesth Plast Surg 2013;37:290-302.

7. Holmich LR,Vejorg IM, Conrad C, Sletting S, Hoir MM, Fryzek JP, McLaughlin JK, Kjoleer K, Wilk A, Friis S. Untreated silicone breast implant rupture. Plast Reconst Surg 2004; I |4:204- I4.

8. Pinchuk V, Tymofii O, Tkach O, Zamkovoy V. Implant rupture after augmentation mammoplasty. Aesth Plast Surg 201 3;37:60-7.

9. Khan UD. Mondor's disease: a review of the literature and a case report. Aesthetic Surg J 2009;29:209-12.

10. Khan UD. Implant rupture and ante-grade excision of axillary siliconoma through implant pocket.A case report and literature search.J Muhamm Med Coll 20I0; I:56-60.

II. Khan UD. Breast autoinflation with sterile pus as a marker of implant rupture: single- stage treatment and outcome for five consecutive cases. Aesth Plast Surg 2009;33:58-65.

12. Khan UD. Left unilateral breast autoinflation and intraprosthetic collection of sterile pus: an unusual operative finding of silicone gel bleed with silicone lymphadenitis. Aesth Plast Surg 2008;32:684-7.
13. Khan UD. Poly implant prothese (PIP) incidence of device failure and capsular contracture: a retrospective analysis. Aesth Plast Surg 2013;37:90613.

14. Robinson OG Jr, Benos DJ, Mazochi C. Spontaneous autoinflation of saline mammary implants: further studies. Aesth Surg J 2005;25:582-6.

I5. Cheng NX, Zhang YL, Luo SK, Zhang XM, Hui L, Chen YL, Sheng SY,Wu DH, Wang HB, Li P. Late haematoma, seroma and galactocele in breast injejected with polyacrylamide gel. Aesthetic Plast Surg 201 I;35:365-72.

16. Kang GC, Ong YS. Large unilateral breast autoinflation after breastfeeding linked to polyacrylamide hydrgel injection augmentation mammoplasty. Aesthetic Plast Surg 20I I;35:122-4.

17. Mazzochi M, Dessy LA, Corris F, Scuderi NA clinical study of late seroma in breast implantation surgery. Aesthetic Plast Surg 2012;36:97-I04.

18. Park BY, Lee DH, Lim SY, Pyon JK, Mun GH, Oh KS, Bang SI. Is late seroma a phenomenon related to textured implants? A report of rare complication and a literature review. Aesthe Plast Surg 2014;38:129-38.

19. Pinchuk V, Tymofii O. Seroma as a late complication after breast augmentation. Aesthe Plast Surg 201 I;35:303-14.

20. Raso DS, Green WB, Metcalf JS. Synovial metaplasia of a periprosthetic breast capsule. Arch Pathol Lab Med 1994; I 18:249-5I.

2I. Rupini A, Frame JD, Kamel D. Lymphomas associated with breast implants: a review of the literature. Aesthet Surg J 2015;35:533-44.

22. Brody G, Deapan D, Taylor CR, Printer-Brown L, House-Lighner SR, Anderson JS, Carlson G, Lechner MG, Epstein AL. Anaplastic large cell lymphoma in women with breast implants: analysis of 173 cases. Plast Reconst Surg 2015; 135:695-705.

23. Bengtson B, Brody GS, Brown MH, Glicksman C, Hammond D, Kaplan H, Maxwell GP, Oefelein MG, Reisman NR, Spear SL, Jewell ML; Late Periprosthetic Fluid Collection after Breast Implant Working Group. Managing late periprosthetic fluid collections (seroma) in patients with breast implants: a consensus panel recommendation and review of the literature. Plast Reconst Surg 201 I; 128: I-7. 